stantial honours that were showered upon him for many years, from grants of money to honorary distinctions of the highest order, must have gone far to compensate for a malady which had for several years left him bed-ridden. The high reputation he so suddenly acquired, more especially in England, was doubtless mainly due to the friendship of Sir Charles Lyell, who constantly quoted his works, almost to the exclusion of those of other writers on similar subjects. His quickness in seizing the characters of even fragments of fossil leaves, his aptitude in describing them combined with the boldness of his inductions and a certain grace of diction, centred attention on his work, and unconsciously diverted it from his eminent contemporaries, Unger, Goeppert, Saporta, and Ettingshausen. The place he occupied was unique, and his opportunities were proportionally great; his loss will be felt, for it will be difficult to find workers, as competent, either able or willing to dispose with such rapidity of the constantly increasing material brought from distant, and especially Arctic, expeditions

The subject which he had thus made his own is one of exceptional difficulty, both from its wide range and the character of the material to be dealt with, and the path which he trod with such assured steps will be trodden by others with doubt and hesitation. If imitation is the sincerest form of flattery, then was Heer most amply flattered, for nearly all works on the newer fossil floras have been modelled on his bases, and he has become the founder of a school which bids fair to monopolise for some time to come this branch of palæontology. It is no disrespect to the dead to mention the open secret that nearly all English botanists, and very many geologists, have doubted the possibility of determining, except in rare instances, the detached and broken leaves which make up nine-tenths of the Tertiary floras. It is fortunate that Heer's temperament was sanguine, and his belief in his power to interpret the material unlimited, else the marvellous Tertiary floras from the Arctic circle, which so profoundly exercise the imagination, would have remained a sealed book. His powers are the more surprising, as his health does not appear to have permitted much travel, a winter spent on the cultivated side of Madeira seeming to have been his only actual acquaintance with extra-European floras. Much of his work, too, was produced under conditions the reverse of favourable for exact determination and comparison: a friend relates that when calling to convey one of the numerous awards made to him by English scientific bodies, he found the Professor lying down with a small table arranged to cross the bed, upon it being specimens which he named while an assistant made drawings.

Besides the fossil floras and insect faunas of his own country, his works comprise, among many otbers, descriptions of the Carboniferous, Jurassic, Cretaceous, and Tertiary floras from round the Arctic circle, and from Germany, Austria, Italy, Portugal, and even more distant countries. In 186 I he was invited to England to describe the Tertiary flora from Bovey Tracey, and a work appeared upon it in the Phil. Trans. of the following year. It is certainly strange that this and nearly the whole of the fossil floras containing dicotyledons examined by him have been referred to the Miocene age, and certain prevailing types seem to recur in the greater part of them ; but it is not our province to discuss the correctness of these views here. He was much in earnest and zealous in the extreme, and the importance and value of his work, including as it does figures and descriptions of species which may almost be numbered by the thousand, is incontestable. So much accomplished, in spite of ill health and probably with less extensive herbaria to consult than are available in this country, commands respect; and however the study of fossil plants may rank in the time to come, Heer's name will for ever be bound up with it as its great pioneer.

\section{THE BACKWARD STATE OF CHEMISTRY IN ENGLAND}

$\mathrm{I}$ the address of the President of the British Association last year the report as to progress in one of the principal Sections, that of Chemistry, is certainly a very meagre one. It is indeed confined to a general statement of the value of materials derived from coal and coal-tars, \&c., and cannot, strictly speaking, be termed chemical. Again, in the address of the President of the Chemical Section, the existence of such a branch or division of chemistry as that termed "organic," and in which more perhaps has been done during the past twenty years than in mineral chemistry during the century, is completely ignored. And unfortunately the reason does not seem far to seek, for very few of the papers presented to the section had direct connection with the chemistry of carbon.

But it is not only at the British Association meetings that this neglect of organic chemistry occurs, but even at the Chemical Society itself the number of contributions to this section of chemistry is very small. In $188 \mathrm{I}$, out of more than eighty communications to the Society only about thirty are relating to carbon compounds. In 1882 the proportion is somewhat greater-thirty-one out of sixty-five. It would be perhaps very unfair to institute a comparison between our Chemical Society and a much younger one, that of Berlin, as they are somewhat different in constitution: and the feeding ground, if it may be so called, is more extensive in the one case than in the other, but still the disparity in number of papers is scarcely to be accounted for in this way.

Chemistry generally, and especially the so-called organic chemistry, appears to have been very much neglected for some years past in this country.

The cause of this lagging behind, especially in a science of such infinite practical applications as chemistry, by this country is somewhat difficult to understand.

We certainly have not the number of chemical schools in England as in Germany, but making allowance for that and comparing the past decade in the two countries we appear to be grievously bebind, both in number of investigations as well as in their theoretical or practical importance.

The cause can scarcely be attributed to any want of energy or appreciation of the value of research on the part of our manufacturers, for they are in many instances obliged to seek assistance out of the country. It seems to some extent rather to be owing to a non-appreciation of the science by the general public, although in its more elementary stages it is more extensively taught than in any other country, and this non-appreciation reacts injuriously on the schools themselves. Although such an intensely practical science and capable of such varied applications, the chemical investigator must pass over many weary stretches of complex and to all appearance purely theoretical and useless work before reaching a brilliant practical result.

Unfortunately, until quite recently but few of our schools were so constituted. and equipped that a student might work on anything like equal terms with his fellow in a German school.

Now, however, we have a goodly number of chemical schools rising up, with in many cases professors trained in German laboratories. But in many of these the professor labours under the great disadvantage, not only to himself and the science, but to the students, that he has too much mere routine teaching and too little time for that original work, or researcb, which acts so powerfully in encouraging and stimulating his students to get more than a mere insight into the working and mechanism of the science, and become investigators themselves.

The cost of working in an English laboratory is somewhat greater than in a German one, but this difference is 
no longer great, and does not by any means account for the difference in results between the two countries. The German student as a rule works very much longer, that is, he is a student for a longer time than the English student, who too often commences his study of chemistry not as a mental training but as a means to an end: to become a public analyst or a works analyst, and who dejires to learn only as much as is absolutely necessary for some particular line he has chalked out for himself; or, worse still, to "pass" some "examination."

The importance of chemistry, especially that more regular and systematic chemistry of the carbon compounds; as a philosophical training is not yet by any means recognised in this country. And it is to be feared that until this is remedied we shall still remain, in spite of new schools, in a backward position.

According to an authority like Prof. Wundt, even qualitative and quantitative analysis are, as logical methods, superior to mathematical. ${ }^{1}$

There is no reason to suppose that the ordinary English student is inferior to any other, and when this subject is put before him in a proper light, as a mental training of the highest order, and not simply a mechanical sort of process, more cheerful results may be looked for. But the students in our higher schools and universities should not stop at qualitative and quantitative analysis, but if possible do some synthetic work, as by this only is a real grasp of the science to be obtained.

When once we get a substratum of well-trained students, not simply analytical machines, or examinationpassers, we shall not have long to wait for results of theoretical and also practical interest.

But our professors must also bestir themselves. In very few institutions in England are more than elementary courses of lectures given, generally the same thing one session after another. The professor should always be practically engaged in research work, so that his students may have a real example to follow. This of course can only take place when the present disproportionate amount of teaching is reduced. Certain it appears that the enthusiasm and rapid advance of the students working in a German university laboratory is in a great measure, probably entirely, due to the example of the professor's working.

\section{THE CHOLERA BACILLUS}

THE Report in which Dr. Koch, chief of the German Scientific Expedition, embodies the results hitherto obtained by him and his assistants with regard to the cholera in Egypt, deals in a very guarded manner with the question of the discovery of a definite cholera bacillus. As the result of experiments carried out both on living and dead cholera subjects, it appears that, whereas no distinct organism could be traced in the blood and in the organs which are so frequently the seat of micro-parasites, yet bacteria having distinct characteristics and resembling somewhat in size and form the bacilli found in glanders were discovered in the intestines and their mucous linings; and this under circumstances which seemed to identify them with the disease from which the patients were suffering. Thus, their existence in the intestinal membranes was obvious so soon after death that they could not have been brought about by any post-mortem changes; they were present in the case of all patients who were actually suffering from the disease, and in the bodies of all those who had died of it, whereas they were abjent in the case of one patient who had had time to recover from cholera but who had died of some secondary complication; and they were not discoverable in the case of patients who, during the cholera epidemic, succumbed to other diseases. And further, the same bacillus had been met with by Dr. Koch, a year previously, in the case of four patients who had died of cholera in India, and portions of whose intestines had been forwarded to him for examination.

From these circumstances Dr. Koch feels justified in provisionally holding the belief that these bacilli are in some way related to cholera, but as yet he is not prepared to say whether they are the cause or the effect of that disease. The number of cases which the Scientific Expedition were able to utilise for the purposes of their inquiry was very limited, and it is also suggested as possible that some of the experiments were vitiated owing to the circumstance that the disease was already subsiding in intensity when the investigations were commenced. Especially does Dr. Koch suggest that this may account for the invariable failure to produce cholera in any of the lower animals into whose bodies the intestinal secretions were inoculated; but as to this it must be remembered that human diseases are rarely communicable to other animals, and that, as regards enteric fever, a disease which etiologically and otherwise has many points of resemblance with cholera, every effort to communicate it to other mammalia has hitherto invariably failed. But the failure of infective power which may very possibly be associated with the declining stage of an epidemic would be very likely to interfere with experiments having for their object the isolation and cultivation of the bacillus, and hence we are glad to learn that Dr. Koch is to continue his investigations in India, where the varying stages of the disease can easily be met with. In the meantime, however, it will be well to remember that Drs. Lewis and Cuningham have, notwithstanding laborious microscopic and other researches in India, hitherto failed to identify any of the organisms they have met with as specifically related to cholera.

One point is set at rest by Dr. Koch's Report, and that relates to the actual nature of the disease which has been epidemic in Egypt. Both pathologically and otherwise he declares it to be identical with Asiatic cholera.

\section{NATIONAL TRAITS IN SCIENCE}

THERE are at present three principal currents of scientific work-German, English, and French. The scientific writings of each nationality are characteristic, and, taken as a whole, offer in each case distinctive qualities. German influence is now predominant over the scientific world, as French influence was uppermost during the earlier part of this century; but the sway of Germany over Western thought is far more potent and widespread than was ever that of France. As students once gathered in Paris, so they now flock to Germany and thence back to their own lands they carry the notions of German science, and labour to extend, imitate, and rival them. Thus German ideas have been spread abroad, and established in foreign countries. This has set a common standard for scientific work, which is accepted in most European countries. German influence is evident by its effects in Switzerland, Russia, Italy, Poland, Belgium, England, and America, and in degrees indicated by the order given: in France, Spain, and Portugal it is hardly noticeable. Holland and the Scandinavian countries have for many years achieved so much and so excellent work that their scientific development may be said to have accompanied rather than to have followed that of Germany.

German science has unquestionably distinctive qualities. Its pursuit is a special and honoured calling, attractive to the highest talent: its productions have the stamp of professional work. The German scientific man is first and principally an investigator: he is obliged to be so, otherwise he loses in the race. He wins his posi- 